\title{
Prevalence of and Risk Factors for Latent Tuberculosis Infection among Healthcare Workers of Directly Observed Tuberculosis Treatment Centers of Kathmandu, Nepal
}

\author{
Shah $\mathrm{NP}^{1 *}$, Sultana $\mathrm{R}^{2}$, Lal BK${ }^{2}$, Bhattachan $\mathrm{A}^{1}$ and Shah $\mathrm{G}^{3}$ \\ ${ }^{1}$ National Tuberculosis Control Center, Thimi, Nepal \\ ${ }^{2}$ SAARC TB and HIV/AIDS center, Kathmandu, Nepal \\ ${ }^{3}$ Hope International College, Lalitpur, Nepal. \\ *Corresponding author: Shah NP, National Tuberculosis Control Center, Thimi, Nepal. \\ To Cite This Article: Shah NP, Sultana R, Lal BK, Bhattachan A, Shah G. Prevalence of and Risk Factors for Latent Tuberculosis Infection among \\ Healthcare Workers of Directly Observed Tuberculosis Treatment Centers of Kathmandu, Nepal. Am J Biomed Sci \& Res. 2021 - 13(5). AJBSR. \\ MS.ID.001901. DOI: 10.34297/AJBSR.2021.13.001901.
}

Received: 眥 July 07, 2021; Published: 眥 July 23, 2021

\begin{abstract}
Introduction: The object of this study was to assess the burden of latent tuberculosis (TB) infection among the healthcare workers at centers for directly observed treatment (DOT) for TB in Nepal and to describe associated risk factors for LTBI in this population. It is very important to measure prevalence of LTBI among high risk group as WHO suggest to treat LTBI in all high risk groups to eliminate TB. BCG coverage in Nepal is 90.9\% according to department of health service in 2019.

Methods: This was a cross-sectional study conducted from May 2019 to March 2020 at the 113 DOT centers across Kathmandu district. With two healthcare workers per DOT center on average, the total number of study participants was 226. After obtaining written consent, the trained data collectors interviewed healthcare workers with a predesigned questionnaire for risk analysis. Those with no symptoms of TB were administered TST. The result was read in 72 hours and recorded in millimeters. To increase the sensitivity, the TST reading of $\geq 5 \mathrm{~mm}$ was regarded as positive TST and samples were collected for IGRA.
\end{abstract}

Results: TST was used as the screening tool (30\% prevalence by cut off $10 \mathrm{~mm})$ and IGRA as the confirmatory test, $17.6 \%(95 \%$ CI 13.08 23.44) for the healthcare workers studied had LTBI with the duration of employment as a healthcare worker as an independent risk factor for LTBI (adjusted OR 1.06, 95\% CI $1.01-1.11, \mathrm{p}=0.006$ ) after adjusting for other factors.

Conclusions: This study suggests that, in Nepal, IGRAs should serve as a necessary confirmatory test for diagnosis of LTBI among healthcare workers before starting preventive therapy, as TST may be false positive due to BCG vaccination and that the duration of employment as a healthcare worker is an independent risk factor for LTBI.

Keywords: DOT, IGRA, LTBI, TST

\section{Introduction}

The World Health Organization estimates that in 2019, an estimated 10 million people fell ill with tuberculosis (TB) worldwide. TB is present in all countries and age groups [1]. In Nepal, tuberculosis is the sixth leading cause of death with an estimated 42000 new TB cases in the year 2019 [2]. Attempts to estimate the reservoir population of tuberculosis - people with latent TB infection have been made. A recent re-estimate has reported that over one-quarter of the world's population (1.7 billion people) have LTBI [3]. BCG coverage in Nepal is $90.9 \%$ according to department of health service in 2019. 
It is, therefore, important that the people at high risk be screened and treated for LTBI. It confers benefit by preventing the active TB disease and decreasing the reservoir population $[4,5]$. The WHO End TB Strategy calls for targeted screening and treatment of high-risk individuals in its quest for TB elimination by 2035 [6]. Healthcare workers, particularly those caring for patients with tuberculosis, are among the high-risk individuals due to their repeated contacts with the patients with TB as well as variable TB infection control practices in the healthcare settings. It has been found that healthcare workers have more than two times higher risk of LTBI in comparison to the general population [7]. Guidelines have recommended screening and treatment of LTBI of healthcare workers based on the background TB epidemiology, available resources and possible harms of treatment $[1,8]$. In Nepal, the majority of the patients with TB receive care from directly observed TB treatment centers across the country and the healthcare workers at these centers are at higher risk for tuberculosis [2]. However, limited data on the burden of TB or LTBI among the Nepalese healthcare workers have been reported.

In this study, we aim to estimate the prevalence of LTBI among the healthcare workers at directly observed TB treatment centers of Kathmandu district. We also aim to assess the risk factors for latent TB among these populations. The information obtained will provide evidence of the existing occupational risk of infection in health care settings.

\section{Methods}

This was a cross-sectional study. Study site was the directly observed TB treatment (DOT) centers under the National TB Program (NTP) are responsible for a large proportion of TB care in Nepal. Due to resource constraints, this study has been confined to the DOT centers from Kathmandu District - the country capital. There are 113 DOT centers across Kathmandu district. All these DOT centers were included in the study. Study Population was the healthcare workers at the DOT Centers of Kathmandu District Sampling unit was the healthcare workers of the DOT centers of Kathmandu District. The objective of this study is to assess the burden of latent tuberculosis among the healthcare workers at directly observed TB treatment centers and describe the risk factors for the same.

The sample size was calculated by the formula $\mathrm{n}=\mathrm{Z} 2 \mathrm{P}(1-\mathrm{P}) /$ $\mathrm{d} 2$ where $\mathrm{Z}$ is level of confidence taken as $1.96, \mathrm{P}$ is expected the prevalence of LTBI among the healthcare workers taken as $41 \%$ (the pooled prevalence value corresponding to the TB incidence of Nepal) and d is the degree of precision taken as $10 \%$. The sample size thus derived was 93. Because the cluster sampling technique was applied, it was multiplied by the design effect of 2 . An additional $20 \%$ non-response rate was estimated, and the final sample size was 223. With two healthcare workers per DOT center on average, the total number of study participants was226.
Inclusion criteria include healthcare workers at the DOT centers who encounter the patients with TB and healthcare workers without the prior or current history of TB. Exclusion criteria includes pregnant females and previous or current active tuberculosis.

The data collectors, after training, visited each DOT centers of Kathmandu District and identified the healthcare workers as the study participants. After obtaining informed written consent, the data collectors interviewed healthcare workers with a predesigned questionnaire. Those with no symptoms of TB were administered TST. The result was read in 72 hours and recorded in millimeters. To increase the sensitivity, the TST reading of $\geq 5 \mathrm{~mm}$ was regarded as positive TST and samples were collected for IGRA. Those who had one or more symptoms of active TB under went further evaluation for active TB by X-Ray Chest and sputum smear examination for AFB. Those study participants in whom active TB was ruled out underwent the interview and TST administration as other study participants. Those healthcare workers who had positive TST underwent IGRA (QuantiFERON TB Gold). The data collector obtained a whole blood sample from these healthcare workers and subjected to IGRA at the outsourced laboratory. Those with positive IGRA were regarded as having LTBI. These study participants were offered a three-month course of Isoniazid and Rifampin therapy. Those with negative TST were regarded as having no LTBI and no further testing was done.

Data entry was done in Microsoft Excel 2016 and analyzed in R (R Core Team (2019). R Foundation for Statistical Computing, Vienna, Austria). Descriptive statistics were used to summarize the sociodemographic and other characteristics of the study participants using mean $( \pm$ Standard Deviation [SD]) or median (Inter-Quartile Range [IQR]) for continuous variables and proportions for categorical variables. Appropriate univariate statistical tests were used to assess the association of LTBI with the potential risk factors from earlier studies using the odds ratio as a measure of association. The factors found significantly associated with LTBI in the univariate analyses were analyzed further by binary logistic regression and the adjusted odds ratio was calculated. The goodness of fit was tested, and the accuracy of the model was determined along with its $95 \%$ CI. A p-value of less than 0.05 was considered significant. Ethical approval was obtained from the Nepal Health Research Council.

\section{Results}

Among the 226 healthcare workers, two had symptoms (cough for more than two weeks) suggestive of active tuberculosis. The $\mathrm{X}$-ray chest and sputum smear of these participants tested negative for active pulmonary tuberculosis. Therefore, all the 226 study participants were evaluated for LTBI and the data analyzed. There were $53(0.6 \%)$ data points missing. There were no systematic interactions between the missing data points. 


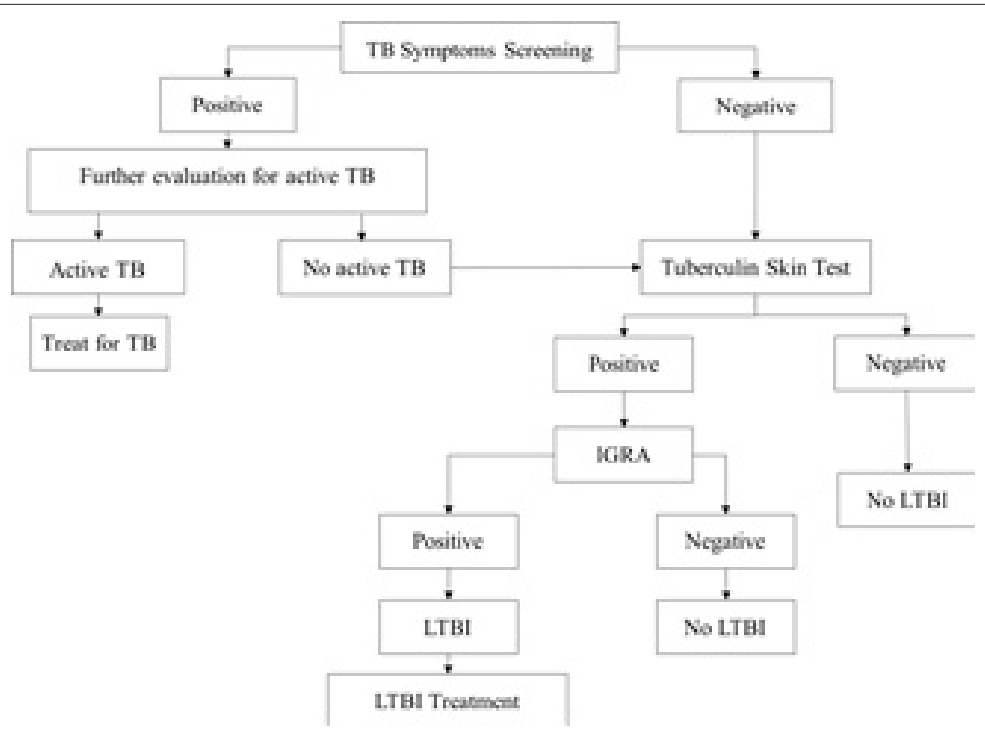

Figure 1: Algorithm for the diagnosis of latent tuberculosis infection.

The median age of the study participants was 40 years (IQR 33 - 46) with a minimum age of 20 years and the maximum age of 60 years. Most of them belonged to the 40 to 50 years category. A majority of them $(140,61.9 \%)$ were females and the rest were males.

Most of them (199, 88\%) were from the government centers and were allied health professionals. Senior Auxiliary Health Worker was the most common position $(53,23.4 \%)$ followed by Health Assistant (45, 19.9\%).

The median duration of employment as healthcare workers was 10 years (IQR 4.75 - 20) with most of the study participants having work experience of 0 - 10 years.

Most of the study participants $(159,71.9 \%)$ reported that they were involved in sputum collection. Almost all the study participants $(221,97.7 \%)$ reported that they were involved in patient counseling.

The median number of patients per day served by the study participants was 7 (IQR 3-15) with most of the study participants serving 0 - 20 patients per day.

Only 16 (7.1\%) study participants reported knowing about tuberculosis disease in colleagues and $25(11.2 \%)$ study participants reported to have tuberculosis disease in family members.

More than half of the study participants (121, 54.5\%) had received training in TB infection control and $(132,60.2 \%)$ reported knowing that there was TB infection control policy in their healthcare facility?
There were 169 (74.7\%) study participants who reported to have been vaccinated with BCG and all these participants had a BCG vaccination scar.

A majority of the study participants $(195,87 \%)$ were nonsmokers.

There were 52 (23\%), study participants, with one or more of the chronic illnesses with systemic hypertension being the most common chronic illness, seen in 28 study participants.

A majority of the study participants had BMI in the range of 20 - 25 with a median BMI of 24.9 (IQR 22.9 - 27.5).

The median TST reading was $5 \mathrm{~mm}$ (IQR 0-10) with most of the study participants had $<5 \mathrm{~mm}$ reading (Figure 2 and Table 1 ).

\begin{tabular}{|c|c|c|}
\hline \multicolumn{3}{|c|}{ Table 1: Number of participants with different TST cut-offs. } \\
\hline Cut-off in TST & Number & Percentage \\
\hline$<5 \mathrm{~mm}$ & 111 & $49.12 \%$ \\
\hline$\geq 5 \mathrm{~mm}$ & 115 & $50.88 \%$ \\
\hline$\geq 10 \mathrm{~mm}$ & 68 & $30.09 \%$ \\
\hline$\geq 15 \mathrm{~mm}$ & 28 & $12.39 \%$ \\
\hline
\end{tabular}

With the TST reading of $5 \mathrm{~mm}$ or more as a cut-off for positive TST results, 115 (50.8\%) participants had positive TST results (Figure 3).

Of the 115 study participants with positive TST results, a whole blood sample for all these participants was obtained for IGRA, 40 samples tested positive (Figure 4). The prevalence of latent TB infection was $17.6 \%$ (95\% CI 13.08 - 23.44). 

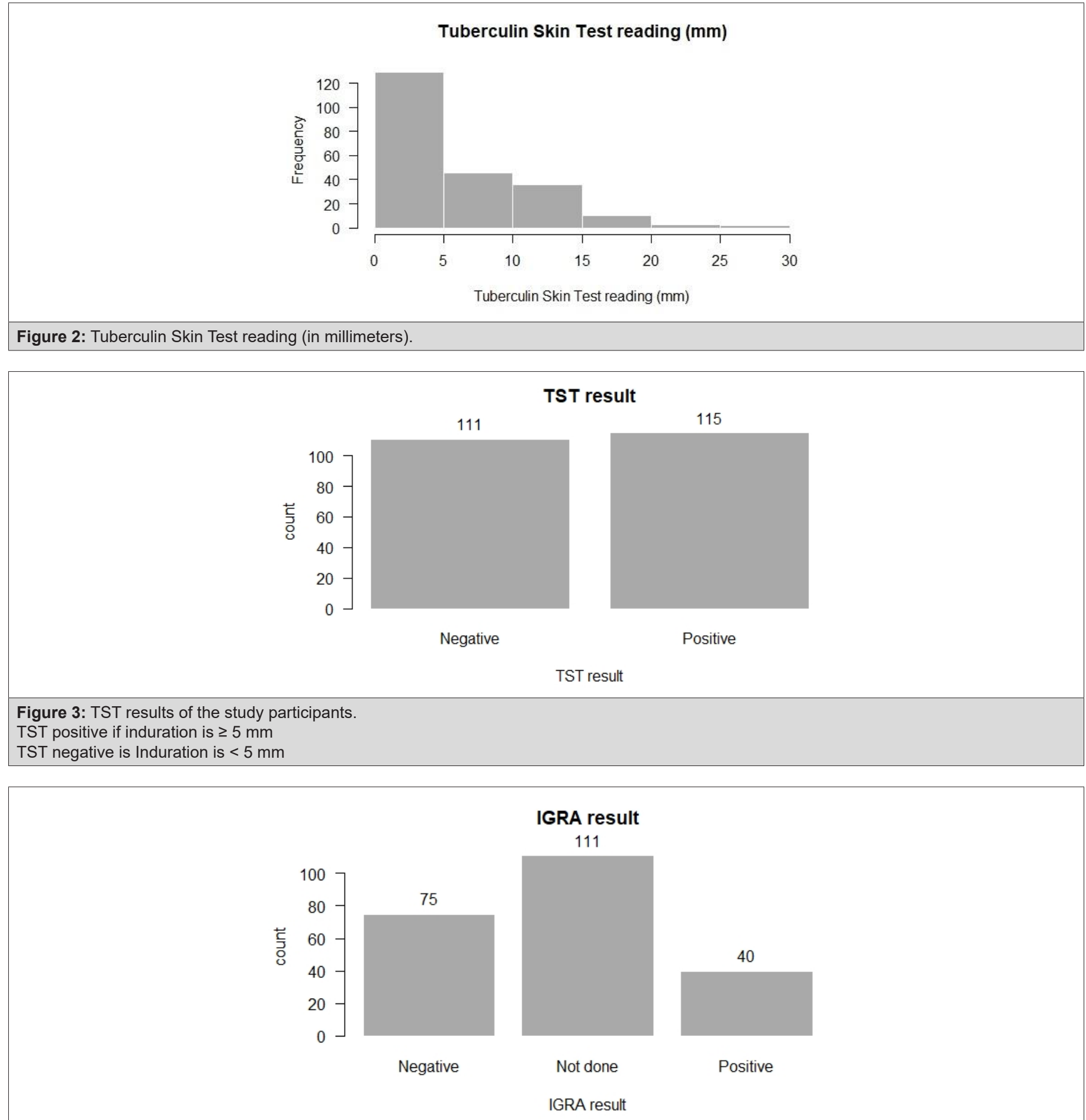

Figure 4: IGRA test results.

On univariate analyses between potential risk factors and LTBI, age, duration of employment as a health worker, number of patients encountered per day and TB in colleagues were found to have a significant association with LTBI (Table 2). A multivariate logistic regression model was fitted with these variables as independent variables. Because there was multicollinearity between age and work experience, only work experience with lower inflation factor was included in the model. The final model, thus obtained, was found to be a better fit to the data than the intercept only model $(\chi 2=12.96, \mathrm{df}=3, \mathrm{p}=0.004)$ and had an accuracy of $81.08 \%(95 \%$ CI 64.84, 92.04). The employment duration as health workers was found to be an independent risk factor for LTBI (adjusted OR 1.06, 95\% CI 1.01 - 1.11, p = 0.006) (Figure 5). 
Table 2: Risk factors for latent tuberculosis infection.

\begin{tabular}{|c|c|c|c|c|c|c|}
\hline \multirow[b]{2}{*}{ Risk Factors } & \multicolumn{2}{|l|}{$n(\%)$} & \multirow[b]{2}{*}{$p$ value } & \multirow{2}{*}{$\begin{array}{l}\text { Odds Ratio }(95 \% \\
\text { Confidence Interval) }\end{array}$} & \multirow{2}{*}{$\begin{array}{l}\text { Adjus ted Oodds Ratio } \\
\text { (95\% Confidence } \\
\text { Interval) }\end{array}$} & \multirow[b]{2}{*}{ p value } \\
\hline & Latent TB Inffection ( $n=40$ ) & No Latent TB & & & & \\
\hline Age in years (Mean \pm SD) & $42.64( \pm 7.4)$ & $38.88( \pm 9)$ & 0.014 & $1.05(1.01-1.09)$ & & \\
\hline Sex & & & & & & \\
\hline $\begin{array}{l}\text { Femmle } \\
\text { Mals }\end{array}$ & $\begin{array}{l}27 \\
13\end{array}$ & $\begin{array}{l}113 \\
73\end{array}$ & 0.425 & $0.75(0.36-1.54)$ & & \\
\hline Type of health facility & & & & & & \\
\hline $\begin{array}{l}\text { Government } \\
\text { Non-Goverment. }\end{array}$ & ${ }_{7}^{33}$ & $\begin{array}{l}168 \\
20\end{array}$ & 0.237 & $1.78(0.84-4.33)$ & & \\
\hline Position & & & & & & \\
\hline $\begin{array}{l}\text { Allied heath profes sional } \\
\text { Nursing profess ional }\end{array}$ & 21 & 123 & & & & \\
\hline 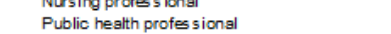 & $\begin{array}{c}1 \\
11\end{array}$ & $\begin{array}{l}12 \\
35\end{array}$ & $\begin{array}{l}0.501 \\
0.144\end{array}$ & $\begin{array}{l}0.48(0.02-2.68) \\
184(0.78-412)\end{array}$ & & \\
\hline Laboratory profess ional & 7 & 18 & 0.085 & $258(0.89-6.81)$ & & \\
\hline Sputum collection & & & & & & \\
\hline $\begin{array}{l}\text { No } \\
\text { Yes }\end{array}$ & $\begin{array}{r}9 \\
30\end{array}$ & $\begin{array}{l}53 \\
129\end{array}$ & 0.447 & $1.36(0.62-3.23)$ & & \\
\hline Patient cours eling & & & & & & \\
\hline $\begin{array}{l}\text { No } \\
\text { Yes }\end{array}$ & $\begin{array}{c}1 \\
39\end{array}$ & $\begin{array}{c}4 \\
182\end{array}$ & 0.892 & $0.85(0.12-17.01)$ & & \\
\hline $\begin{array}{l}\text { Work experience in vears (Mean } \pm \text { SD) } \\
\text { No. of patients encountered der d d (Mean } \pm \text { SD) }\end{array}$ & $\begin{array}{c}19.48(8) \\
168(15)\end{array}$ & $\begin{array}{r}15.12(2.8) \\
11.22(144)\end{array}$ & 0.006 & $1.08(1.01-1.10)$ & $1.06(1.01-1.11)$ & 0.006 \\
\hline $\begin{array}{l}\text { No. of patients encountered per day (Mean I SD) } \\
\text { TB in colleague }\end{array}$ & $18.8(15.2)$ & $11.22(14.4)$ & 0.040 & $1.02(1.00-1.04)$ & $1.01(0.98-1.03)$ & 0.280 \\
\hline $\begin{array}{l}\text { No } \\
\text { Yes }\end{array}$ & 34 & 173 & 0.042 & $3.05(0.98-8.80)$ & $281(072-10291$ & 0.12 \\
\hline$T B$ in tamily & & & & & 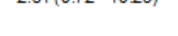 & 0.12 \\
\hline $\mathrm{N}_{\text {Yes }}^{\text {No }}$ & 34 & 164 & 0.404 & $1.52(0.52-3.91)$ & & \\
\hline $\begin{array}{l}\text { Yes } \\
\text { Trained in TB infection control }\end{array}$ & & 19 & & & & \\
\hline No & 20 & 81 & 0.528 & $0.80(0.40-1.59)$ & & \\
\hline $\begin{array}{l}\text { BCG Vaccination } \\
\text { BCs }\end{array}$ & & & & & & \\
\hline Do not know & 2 & 8 & & & & \\
\hline $\begin{array}{l}\text { No } \\
\text { Yes }\end{array}$ & $\begin{array}{c}7 \\
31\end{array}$ & $\begin{array}{l}40 \\
138\end{array}$ & $\begin{array}{l}0.888 \\
0.895\end{array}$ & $\begin{array}{l}0.70(0.13-5.27) \\
0.89(0.21-8.14)\end{array}$ & & \\
\hline Smoking & & & & & & \\
\hline $\begin{array}{l}\text { No } \\
\text { Past smokes }\end{array}$ & ${ }_{2}^{34}$ & 然1 & 0.948 & $0.94(0.14-3.80)$ & & \\
\hline Current smoker & 4 & 13 & 0.532 & $1.45(0.39-4.41)$ & & \\
\hline Chronic illness & & & & & & \\
\hline $\begin{array}{l}\text { No } \\
\text { Yes }\end{array}$ & $\begin{array}{l}30 \\
10\end{array}$ & $\begin{array}{l}144 \\
42\end{array}$ & 0.742 & $1.14(0.49-2.46)$ & & \\
\hline Body Mas 5 Index in $\mathrm{Kg} / \mathrm{m} 2$ (Mean $\pm \mathrm{SD}$ ) & $25.44(3.3)$ & $25.3(3.7)$ & 0.828 & $1.01(0.91-1.10)$ & & \\
\hline
\end{tabular}

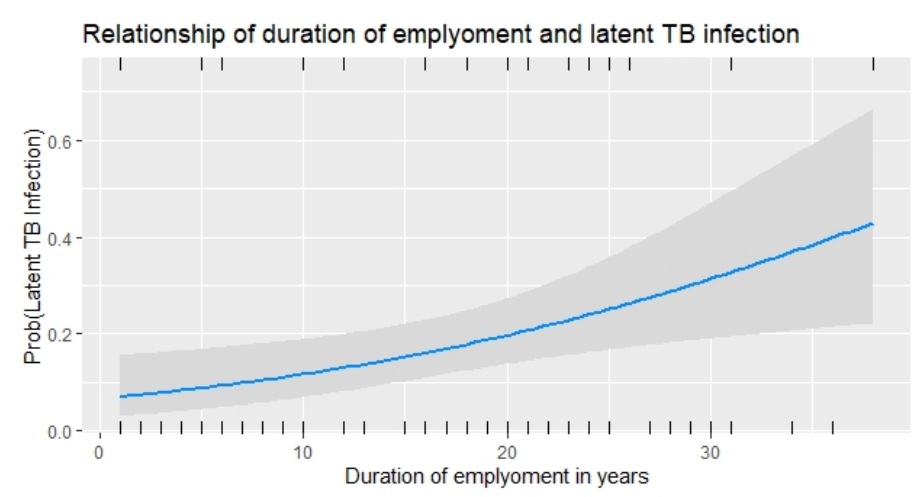

Figure 5: Relationship of the duration of employment and latent TB infection.

\section{Discussion}

The prevalence of LTBI in this study was found to be lower than the pooled estimates of $39 \%$ (based on IGRA results) or $49 \%$ (based on TST results) reported in the updated systematic review and meta-analysis of the studies among healthcare workers from lowand middle-income countries [9]. Several possible explanations could be offered to account for this observed difference.

First, the algorithm for diagnosis of LTBI in this study uses TST as the screening tool to select a subset of the study population and IGRA as the confirmatory test to diagnose LTBI in this population. The implications are twofold. While this strategy strives for higher specificity in LTBI diagnosis, the cost is the lower sensitivity in LTBI diagnosis due to the lower sensitivity of IGRA (done by
QuantiFERON TB Gold in this study). In addition, it does not consider the individuals with TST negative results for IGRA testing and thus does not accommodate the possibility of TST-/QFT+ discordance. Studies estimate that $8.6 \%$ to $15.3 \%$ of the individuals with negative TST could test positive in IGRA $[10,11]$. If TST had been used alone for diagnosis of LTBI, with the standard cut-off of $10 \mathrm{~mm}$ or more, $30.09 \%$ of the study participants would have been regarded to have LTBI, which is comparable to the prevalence of $36 \%$ (95\% CI 21-51) pooled from nine studies from low- and middle-income countries with TB incidence comparable to that of Nepal [9]. Furthermore, the IGRA positivity of $34.7 \%$ would have reflected the prevalence of LTBI had it been used as the LTBI diagnosing tool. This too is comparable to the prevalence of $41 \%$ ( $95 \%$ CI $28-50$ ) pooled from seven studies from similar settings [9]. 
Second, though the TST cut-off of $\geq 5 \mathrm{~mm}$ was used to increase its sensitivity, only one-step TST was used in this study which may have failed to elicit the optimal response of remote TB infection in some individuals due to waned cell-mediated immunity.12 A second TST done 1 - 3 weeks of the first TST (called two-step TST) has been shown to find additional individuals with positive TST [1315]. This phenomenon, known as boosting, increases in the settings with high TB burden and high rate of BCG vaccinations [12]. Use of one-step TST in this study may have missed a subset of study participants who would have tested positive in two-step TST and thus would have been tested for IGRA subsequently, contributing to the LTBI burden estimation.

Third, there are important differences in the study populations in this study and the studies which contributed to the pooled prevalence estimates [9]. Most of the participants (63.7\%) in this study were allied health professionals and none were physicians or general services staff (Figure 7). In addition, there were laboratory and public health professionals included as well in this study. The pooled estimates in the systematic-review have been obtained from the studies that had representations from physicians as well as general services staff. In the stratified analysis reported, the LTBI prevalence was lower in allied health professionals $45 \%$ versus $49 \%$ in overall healthcare workers, based on TST or $31 \%$ versus $39 \%$ in overall healthcare workers, based on IGRA). In nursing professionals, the prevalence estimates are higher (54\% versus $49 \%$ in overall healthcare workers) based on TST and lower (34\% versus 39\% in overall healthcare workers) based on IGRA. Estimates from laboratory or public health professionals were not available for comparison.

The duration of employment as a health worker, found to be a statistically significant risk factor in this study, has been reported as an important occupational risk factor for LTBI in earlier studies as well. In the systematic review and meta-analysis of the studies from low- and middle-income countries, eight studies reported the duration of the employment as one of the risk factors for LTBI, either by TST or IGRA [9]. This suggests that longer the duration of employment as a health worker, longer the duration of exposure with the patients with TB and therefore, higher the risk of getting LTBI. This highlights nosocomial TB transmission as an important occupational problem for health workers. Effective implementation of TB infection control policy in DOT centers, and by extension, all healthcare centers, is apriority.

Limitation of the study was there is no gold standard test for LTBI diagnosis, the accuracy of LTBI prevalence estimation by the algorithm in this study or any other strategy could not be assured. This study was restricted to the health workers at DOT centers of Kathmandu district. This implies that the conclusions derived may not be generalizable to the health workers in other types of facilities or the rest of Nepal.

\section{Conclusion}

It is very important to treat LTBI to eliminate TB from the world. WHO suggest to start treating LTBI in high risk groups beyond less than 5 years and HIV patients in Nepal to eliminate TB. Before starting treatment we should confirm the diagnosis of LTBI. This study suggests that, in Nepal, IGRAs should serve as a necessary confirmatory test for diagnosis of LTBI among healthcare workers before starting preventive therapy and the duration of employment as a healthcare worker is an independent risk factor for LTBI.

\section{Acknowledgements}

I would like to express my sincere gratitude to my seniors Dr Bibek Kumar Lal, Dr Anuj Bhattachan for providing their invaluable comments and suggestion.

My completion of this article could not have been accomplished without the support of Mrs Rabeya Sultana and Mrs Geeta Shah who has assisted me. Financial support was provided by SAARC TB and HIV/AIDS center

\section{References}

1. 2018 World Health Organization. WHO | Global tuberculosis report 2020 [Internet].

2. 2018 National Tuberculosis Program. National Tuberculosis Program Annual Report [Internet].

3. Houben RMGJ, Dodd PJ (2016) The Global Burden of Latent Tuberculosis Infection: A Re-estimation Using Mathematical Modelling. PLOS Med 13(10): e1002152.

4. 1999 American Thoracic Society (ATS) and Centers for Disease Control and Prevention (CDC). Targeted Tuberculin Testing and Treatment of Latent Tuberculosis Infection [Internet].

5. Taylor Z, Nolan CM, Blumberg HM (2019) Controlling tuberculosis in the United States. Recommendations from the American Thoracic Society, CDC, and the Infectious Diseases Society of Amer... - PubMed - NCBI [Internet] 54(RR-12): 1-81.

6. 2019 WHO's new End TB Strategy - The Lancet [Internet].

7. Uden L, Barber E, Ford N, Cooke GS (2017) Risk of Tuberculosis Infection and Disease for Health Care Workers: An Updated Meta-Analysis. Open Forum Infect Dis 4(3).

8. 2005 Guidelines for Preventing the Transmission of Mycobacterium tuberculosis in Health-Care Settings.

9. Apriani L, McAllister S, Sharples K, Alisjahbana B, Ruslami R, et al. (2019) Latent tuberculosis infection in health care workers in low and middleincome countries: an updated systematic review. Eur Respir J 53(4).

10. Pai M, Gokhale K, Joshi R, Dogra S, Kalantri S, et al. (2005) Mycobacterium tuberculosis infection in health care workers in rural India: comparison of a whole-blood interferon gamma assay with tuberculin skin testing. JAMA 293(22): 2746-2755.

11. Machado A, Emodi K, Takenami I, Finkmoore BC, Barbosa T, et al. (2009) Analysis of discordance between the tuberculin skin test and the interferon-gamma release assay. Int J Tuberc Lung Dis Off J Int Union Tuberc Lung Dis 13(4): 446-453.

12. Menzies D (1999) Interpretation of Repeated Tuberculin Tests. Am J Respir Crit Care Med 159(1): 15-21. 
13. Salles CG, Ruffino Netto A, Lapa e Silva JR, Kritski AL, Cailleaux Cesar M, et al. (2007) The presence of a booster phenomenon among contacts of active pulmonary tuberculosis cases: a retrospective cohort. BMC Public Health $7(1): 1-5$

14. Mohammad HA, Esmail MA, Abdelftah MT, Soliman W, Mohammad A, et al (2015) Comparison of the 2-step tuberculin skin test and QuantiFERON-
TB Gold in-Tube test in the screening of latent tuberculosis infection in cancer patients. Egypt J Chest Dis Tuberc 64(3): 681-688.

15. Lien LT, Hang NTL, Kobayashi N, Yanai H, Toyota E, et al. (2009) Prevalence and Risk Factors for Tuberculosis Infection among Hospital Workers in Hanoi, Viet Nam. PLoS One 4(8): e6798. 